\title{
2 Anthropology and Small Populations
}

In a journal that declares its mission to promote discussion between historians and social scientists, the most recent report is that, "though almost all historians profess to revere anthropological insights, the lessons of anthropology still seem to pass many by"; and a veteran of the social sciences, recently looking at all of them together, concluded his survey with the suggestion that they should perhaps listen more to each other. "It would be interesting to hear from historians," for example, "as to what anthropology could do for them."1

The invitation is welcome if for no other reason than its opening upon the past. For anthropology alone among social sciences has focused not only on living samples or populations but on those also that appear to be "frozen in time", as a newspaper account might put it. They offer for study ways of life that resemble those of long ago, while being at the same time susceptible to close observation and description in quantifiable, verifiable terms.

Yet anthropology and history are sister disciplines, exhibiting much overlap or at least close similarities and dealing with essentially the same subject matter: that is, mankind as individuals but still more in collectivities. Either discipline may, as naturally as the other, take in the empire of Shaka kaSenzangakhona in the Transvaal or, in North America, the long story of Plains warfare. ${ }^{2}$ Other populations, although seen as primitive, nevertheless count their citizens in the tens of thousands, even in the hundreds of thousands: the modern Javanese of Clifford Geertz's studies, or many others of a size with the "nations" at least of ancient and medieval times. ${ }^{3}$ Smaller tribes than these are reported as living for generations more or less constantly at war with everyone around them, and thus have had foreign relations in a conventional sense, if nevertheless hidden below the ordinary historical horizon. Examples include the Nuer, the "warfare societies" of New Guinea, and the much discussed Yanomami. ${ }^{4}$

1 Fernández-Armesto (2009) 217; Fish (2000) 552.

2 On Shaka, Ritter (1955) seems to me preferable to D. Wylie's Myth of Iron (2006); on the Plains Indians over some centuries, see Newcomb (1950), writing as an anthropologist; also Voget (1964) 487f. and Nisbett (1990) 259.

3 The Balinese were close to a million in the 1930s, cf. Barnouw (1985) 121; ibid. 37 on the Aymara Indians around Lake Titicaca, some 700,000 studied as one whole culture; and note the 350,000 Toraja in Indonesia, Hollan (1988) 55; 300,000 Bantu in western Kenya described by Wagner (1940) 202; and 170,000 Enga in Papua New Guinea, Feil (1988) 101.

4 The ever-raiding Nuer in Evans-Pritchard (1940) 48, 125; Boehm (1999) 95, New Guinean "warfare societies"; the ever anxious, gloomy Aymara of Bolivia, Barnouw (1985) 38; Nyakyusa in Wilson (1963) 80; Crow Indians in Voget (1964) 487; New Guinean Ok and neighbors, in Morren (1984) 173ff.; Yanomami in Chagnon (1997) 8f., 204 and Borofsky (2005) 121, 175; and Brazilian Mundurucu in Helbling (2006) 173f. 
Normally anthropologists prefer their subject to hold still (history begs to differ). The greater part of their data is synchronic, caught in a snapshot not a video. ${ }^{5}$ Quite aside from the convenience of this, however, it has some justification; for, where, by exception, preliterate cultures have been studied diachronically in the reports of earlier missionaries, travelers, and long-term residents (some, very careful), it is striking how almost unchanging many can be shown to be over very long periods. ${ }^{6}$ They maintain the same integrity that may be seen in any small country such as, let us say, Switzerland. Kinship between history and the social sciences is thus reaffirmed. And if preliterate peoples are made the target of imperial intrusion, they will show a history just like Poland's, for example, or Macedonia's, in a great variety of responses. ${ }^{7}$ They may resist to the very brink of extinction, or instead, they may accept an easy accommodation. There were, for illustration, Ghanaian LoDagaa or the Ivory Coast people, the Beng. The latter put up no opposition at all (though indeed they put up fervent prayers to their ancestors and the deified Earth) against French colonial forces, while their close neighbors fought back according to entirely different traditions. ${ }^{8}$ Their story can be told in the same way as that of modern countries, applying the same rules of the historical discipline; and, vice versa, what anthropologists have to say in explaining these sub-significant narratives, historians can give heed to, and learn as they do so.

A good figure to learn from would be Franz Boas. A German emigré gaining a position in New York's Natural History Museum and then in the 1890s at Columbia University, he focused his investigations first on a people long in touch with the advanced nations and made familiar through their totem poles and potlatch. They were the

\footnotetext{
5 "Anthropologists's problems are generally synchronic", at least in past practice, Evans-Pritchard (1962) 52; Ortner (1984) 149f.; Kuper (1996) 7f. and 29 recording the criticism of Malinowski for caring nothing about the changes that might supervene in the lives of the people observed, since change always complicated his favored functionalist approach; but (p. 126) others like Evans-Pritchard and Gluckman have nevertheless found ways of using historical materials.

6 Generally, Schwartz (1980) 161 or Barnouw (1985) 67; the Bantu in Wagner (1940) 202; American Indians in Hallowell (1955) 127, 132ff., or Manson (1988) 92; Samoans in Freeman (1983) 158, 170; the Indonesian Kedang, in Barnes (1980) 87; the Kenyan Gusii in LeVine (1984) 71 (culture unchanged, 1940s-1970s); or the Pacific Islanders involved in the Kula, below, note 47.

7 Among countless illustrations, see e.g., Nader (1990) 8 on Zapotec village reactions to the intrusions of Mexican federal law; Wilson (1963) 17, 39, and 80 (on the credit loss of a traditional hero-type among the Nyakyusa of Tanzania); similarly among the Lugbara of Uganda, denied a life with war, Middleton (1965) 48; Hogbin (1970) 45 on the consciousness of a falling off from the glory days of previous generations of Solomon Islanders; Ross (1984) 90 on the Ecuadorian Achuara Jivaro; Fleisher (2000) 746ff. on cattle-raiding as almost a way of life in the earlier twentieth century along Tanzania's borders; Feil (1988) 107f. on the Tombema-Enga of New Guinea and (quoted) on Mauss. Mauss wrote about the tee in the 1920s, using data from Malinowski and others; and Hermann (1995) 155ff., 160, and passim, on the New Guinean cargo-cult.

8 Goody (2006) 23 on the LoDagaa; Gottlieb (2000) 55f. on the Beng; Rousseau (2006) 102 on the everpeaceful Venezuelan Piaroa or the Brazilian Xinguanos.
} 
Kwakiutl and their many neighbors of the same traditions. Because of the small size and independence of their communities they were specially suited to study. Of course the observer must be cautious:

\begin{abstract}
There are problems encountered in the investigation into the character of cultures. The more powerfully a master-idea (Leitmotif) dominates within a society, the more it finds expression not only in individuals in a given moment but also in many other members of the society, each with their own nature and in different ways. A somewhat clearer picture will only appear if the reigning form is so strong that it suppresses individual differences... I may perhaps offer an example, that of the Indians of America's northwest coast. The guiding principle here is the unlimited urge to gain and maintain celebrity status (soziales Prestige), and the intense feeling of inferiority if this is in the least little bit diminished. This shows as much through good as through bad actions. Though rank and wealth are prized above all, it nevertheless may happen that criminals (in the terms of the culture) compete with each other in sheer awfulness. Whatever looks like a loss of celebrity produces shame and can only be made good by treatment that correspondingly raises prestige; and, if that is beyond attainment, then - suicide. ${ }^{9}$
\end{abstract}

Boas' object was to grasp a people as one whole, and in this aim of course historians will happily join him, to understand collective behavior.

Among his students were two destined to make his views interesting to a very wide readership: Ruth Benedict and the slightly younger Margaret Mead, "towering figures" as they seemed a half-century later. Both took up and developed the idea that (in Benedict's words) "the study of primitive peoples" can help in the discovery of larger truths since "simpler cultures may make clearer social facts that are otherwise baffling and not open to demonstration". ${ }^{10}$

And with the phrase "social facts" Benedict reminds her readers of one of the great names of the time, the father of sociology as he was to be called, Emile Durkheim. He had used that key phrase to mean certain patterns of behavior which in realist fashion he saw as actual existing objects, out there on their own, first to be distinguished (or simply posited, I would say) and then used as tools of analysis. They were or are institutions, ways of acting that influence every individual alike, beyond the response of any particular person at any particular time. They might be a moral value, or the idea of fair exchange, conceptions of wealth, religious dogmas. "Treat social facts as things," he said; and he had many followers in the social-science world of New York as in London, too. ${ }^{11}$

9 Boas (1936) 262 and 267, in my translation, on the Kwakiutl, on whom he first published in 1925 and wrote to the same effect in 1928, as quoted in Barnouw (1985) 67. But his interest in the Pacific Northwest peoples went back to the 1880 s.

10 Benedict (1934) 55; quoted on the two, Spain (1982) 166.

11 Durkheim (1982) 59, 69 - still the Great Teacher for many social scientists, e.g., Tooby and Cosmides (1992) 25, 27f., etc., accepting Durkheim's realist assumptions with consequent confusion. 
Benedict paid her respects also to two philosophers even better known in her day: Herbert Spencer and Oswald Spengler. She acknowledged the popularity of their huge abstract ideas and generalizations, and offered her own, as for example, "Man, all down his history, has defended his uniqueness like a point of honor. Confucius..."; or again, "Greece... did not carry out... the distrust of individualism... which in Greece was scanted because of forces with which it came in conflict" (where her meaning is not immediately clear). ${ }^{12}$

She goes on about the usefulness of evidence from "primitive peoples", in the passage quoted above: "This is nowhere more true than in the matter of the fundamental and instinctive configurations that pattern existence and condition the thoughts and emotions of the individuals who participate in those cultures. The whole problem of the formation of the individual's habit-patterns under the influence of traditional custom can best be understood at the present time through the study of simpler peoples" - in contrast to understanding all the Greeks, all the West, all China across its millennia. "This does not mean that the facts and processes we can discover in this way are limited in their application to primitive civilizations.” They can be applied to much larger entities. One might, for example, reason from the Zuni to the Greeks, or vice versa. ${ }^{13}$ But the underlying objective in the study of Man remained the discovery of general laws in terms of which data could be assembled in some understandable form, just like the behavior of the celestial society of stars and planets, the latter made rational in their movements thanks to Isaac Newton. The model of the physical sciences was ever the ideal before such early students as Benedict and Mead. So it was and is also for their admired predecessors and their successors to this very day. ${ }^{14}$

If, however, the model of physics or mathematics should prove elusive, nil desperandum! Individual data could always be compared for points of similarity, suggesting larger ideas. As Alfred Radcliffe-Brown believed, in the early days of scientific anthropology, "the comparative method used as an instrument for inductive inference will enable us to discover the universal, essential, characters which belong to all human societies, past, present, and future. The progressive achievement of knowledge of this kind must be the aim of all who believe that a veritable science of human society is possible and desirable."15

12 Benedict (1934) 53ff., quoted; 78, on Spencer and Spengler; on Man, 4; on Greece, 80.

13 Ibid. 79f.

14 Boas' ideal was more empiricist and taxonomic than in the next generation of anthropology, cf. Bennett (1999) 952; but later and to this day, cf. Fish (2000) 553 on "the veneration of physics as the ideal of all science", with other illustrations in my Preface.

15 Radcliffe-Brown (1940) xi; and by successively wider comparisons we advance to "general similarities", "types", and so to "an abstraction only a little way removed from the concrete reality" (of a Durkheimian nature). In another illustration, two very influential anthropologists, Kroeber and Kluckhohn (1952) 181, warn that "as yet we have no full theory of culture. We have a fairly well delineated concept. But... concepts have a way of coming to a dead end unless they are bound together in 
For this empiricist alternative to grand theory, an inspiration lay in the work of the Polish Bronislaw Malinowski, with whose study of the Trobriand Islands modern anthropology may be said to begin. His was a functionalist approach, as it has been called: he assumed that a society's norms and routines would develop in answer to basic needs within each people's particular setting. Thus, the setting and culture made sense and had to be understood together. Yet even Malinowski like others before him and after aspired to something beyond field notes. In italics (1916), he wrote, "Only laws and generalizations are scientific facts, and fieldwork consists only and exclusively in the interpretation of the chaotic social reality, in subordinating it to general rules". ${ }^{16}$

At mid-point in the last century, Max Gluckman, a leader among his fellow anthropologists by that date, could offer them a very satisfactory summing-up of their achievements to date. He recalled Ruth Benedict's familiar work, Patterns of Culture; like Benedict, he also reminded his readers of the Malinowskian attention to specifics and details that he himself especially favored. What they all amounted to was no mere jumble of tableaus of populations, every one more or less minutely portrayed but different from every other. That would be too much like history. What had been assembled was rather an information base from which could be inferred an order governing homo sapiens as a species. He saw his discipline in the same terms as his predecessors. Ultimately, the job was to be "scientific" in the conventional sense, aiming at laws, generalizations, taxonomy:

\footnotetext{
"Faced by a truly enormous variety of tribes, living in diverse environmental situations... we had to provide a systematic morphology of the forms of tribal society and the patterns of its cultures. Our achievement has been considerable. Anthropological monographs in the last forty years have advanced knowledge of tribal politics, economics, domestic relations, ritual and religion and law, until the study of this field is a specialized, academic discipline in itself. Since these studies have raised general theoretical issues about the nature of social life and culture, the various branches of anthropology have been accepted as making a distinctive contribution within the social and human sciences, and have been deployed on peasant and modern industrial societies. In addition, the studies of tribal life by anthropologists helped to eliminate among the most educated people the idea of tribal society as mere savagery."
}

a testable theory."

16 Gluckman (1965) 28ff.; Kuper (1996) 22ff., 33, 149; Malinowski (1979) 1 and 9 (quoted); Stocking (1986) 38ff., Malinowski's empiricist approach even to Freudianism, in the 1920s; and Bennett (1999) 951, choosing Malinowski's long article of 1916, later a book on the Trobriand Islands, as "the first modern, theoretically informed ethnological monograph"; and Shack (1985) 18 choosing "Malinowski's Argonauts[1922] as probably the single most influential publication in the shaping of modern anthropology".

17 Gluckman (1965) 176. 
And if anyone should ask why this spokesman and his colleagues "had to provide a systematic morphology", the answer would no doubt be, that anthropology, psychology, or any of the "-ologies" devoted to the study of Man must aspire to membership among "real” sciences. It couldn't be doubted that the goal was attainable and suited to become the discipline's best contribution to knowledge.

But in this same interwar period, before the job could be finished, the forces of change advanced upon the more remote regions of the world with ever-increasing insistence, giving rise, now, to two answers for every question the visitor might ask: "Yes, that's how it is nowadays with the traders" (or "with the district commissioners", or "state courts", or "prospectors", or "missionaries” or “developers"...) "but our old ways were different". The face of the people turned toward the outside was being transformed, necessarily, with effects eventually registering on internal structures. The whole was no longer itself. Rather, it was made up increasingly of various compromises on the way to becoming modern history. Benedict's "simpler cultures" were destined in all but the most obscure corners of the earth to undergo a complicated deformation; anthropology must include in its observation not only the familiar aspects of life, kinship and so forth, but also "such forces as mechanization, industrialization, suburbanization, and internationalization through tourism and the mass media."18

An unlucky, almost comical illustration can be seen in the account of Jean Briggs. Early in the 1960s, being interested in studying shamanism, she sought out the most isolated Eskimo group she could identify; with enormous effort and at some personal risk she reached it and settled among them; only to discover they had been somehow evangelized over several decades previously. They had all become devout Anglicans, embarrassed by and estranged from their own past. ${ }^{19}$ Marcel Mauss, Durkheim's nephew and follower, saw the consequences of such processes in a certain social custom of New Guinea: "When the gift exchange system of the tee is no more, as Mauss lamented, a new sort of man will be born". ${ }^{20}$ And for a third witnesses, I may quote my friend Weyer in the 1950s: "The last of the truly uncivilized natives are nearly gone. Just when the techniques of anthropology and psychology have reached a useful stage, we find ourselves almost without any primitive people to try them out on". ${ }^{21}$

18 Kottak (1983) viii, in a volume intended to introduce college students to the discipline.

19 Briggs (1970) 2f.; and 4, the Utku are taught to turn their back on their history. It is "bad". For a well analyzed description of the cultural impact of similar colonializing pressures, to be seen among the Sinhalese, cf. Kapferer (2002) 6-17.

20 Kuper (1996) 148 on problems posed to study by colonial influences, and above, n. 6.

21 On the discipline's "ludicrous, not to say tragic, position", see Malinowski (1922) xv; Weyer (1955) 73, 120 (quoted); Southall (1970) 29, on "the melancholy paradox of anthropology”; Marcus and Fischer (1986) 24, on "salvaging cultural diversity, threatened with global Westernization... All peoples are now at least known and chartered"; 36 , "the kind of field sites anthropologists have traditionally 
In more recent decades anyone interested in the varieties of human society untouched or little changed by Western exploitation, by missionizing, and cocacolonisation, could only reach out to that "purity" (call it) through the written record of earlier observers, not through living among them like a good ethnographer. As an example, the Hawaiian natives' sacrifice, if it was that, of Captain Cook in 1779; or by using a description of Iranian nomadic pastoralists of the 1950s and earlier, one might attempt, a half-century later, to reinterpret that record according to the latest theories and comparanda; but the hard evidence all lay in the past. Or one might instead describe the "untouched" as they responsively transformed not only their institutions but their very history to make a better fit with the Western world. ${ }^{22}$ The study of the primitive thus gradually drew to a close, or almost, and with it, the catalogue of specimen societies through which to understand our more complicated ones.

Here had been - here once lay - what historians must surely find useful. Hence my emphasis on the anthropological scene of a generation ago and more, before the world went global. In more modern times what has been increasingly seen around the world has been the reflection of our Western selves, a fact acknowledged in the anthropological discipline itself by adaptations in its goals and methods. But, as "purity" in the target populations has been lost, so lost also are social phenomena similar to whatever is not modern in the peoples and periods that historians study; that is, tribal practices on a small scale, very closely observed. So one might compare chieftains' feasts with a medieval baron's table, or ideas about honor and kin among the peoples of the Pacific Northwest coast, with duels and feuds still in Andrew Jackson's day. ${ }^{23}$ Even more valuable than analogies for the purposes of historians are anthropological approaches, methods, or theories, both those that seem to work and those that don't; and best of all, the idea of collective personality. This last holds out the most promise, in my view, as it is sought and defined by anthropologists.

sought can no longer be found, or even imagined without dissonance", and in the "shrinkage" of the world, all are interdependent, none can be treated as "totally alien"; Bennett (1999) 951, for whom the 1950s and 1960s "marked the end of tribal society and culture"; still more obviously in 1992, when N. A. Chagnon saw how "the world is shrinking and 'unknown' tribes or villages are now very rare" (quoted in Borofsky 2005, 25). See further in www.uncontactedtribes.org for exceptional survivors (mostly in Brazil, also Peru and Colombia).

22 On Captain Cook's death in 1779, Sahlins (1995) 5f., Obeyesekere (1997) 194 and passim, and Bolyanatz (2004) 109ff.; Salzman ((2000) 49-53 on the Bassari in southern Iran known through a book of 1961; Gordon (2004) 64 and passim on the Zambian Lunda and their new "traditions"; Kapferer (2002) 16ff. on the Sinhalese; or other illustrations of ethnography rescued from much earlier publications, Boehm (1999) 95f., Ames (1995) 163-69 or Fleisher (2000) 746f. on the Tanzanian Kuria. By my privileging of early (generally pre-1960) reports of non-European cultures to serve in my discussion of collective personality, it will be clear where I stand on the vexed question of any indigenous collective essence and its possible recovery from a pre-colonial past (on which, see, e.g., Dirlik 1996, 9ff., 23f.). 23 On feasts, see for example Hayden (1995) 22f., quoted further at n. 48. 
I discuss approaches, first, before turning, last, to the matter of a collective character or (in Franz Boas' term, above) Leitmotif.

Interpretive schools in anthropology of the traditional sort have continued to appear in support of rationalism, functionalism, neo-Freudianism, structuralism, empiricism, post-colonialism, or other. The danger of agendas driving interpretation has been duly noted: for example, "actively unscientific" misrepresentations in furtherance of "ideology", in order to support cultural against biological determinism. Boas and the Columbia school had been a too close-bound, in-turned research community. ${ }^{24}$ Prospects of Newtonian certainties we have seen gradually fading. A wit took note of the process: "all the isms had become wasms". ${ }^{25}$ That was in the 1990s in the midst of a contest between the proponents of cultural relativism as against universalism, a contest invoking Marxism and Capitalism and sustained by the best academic presses into the present century. It will need mention again, later. ${ }^{26}$

But beneath theory there remained the techniques of science. These had naturally been applied from the earliest days, even back in the nineteenth century by Franz Boas. A more modern instance was Jessie Bernard's testing (1945) of Margaret Mead's work, which was by that date hugely admired and solidly established in the public mind. Mead had drawn conclusions about sex-differentiation from the comparison of three "preliterate cultures" where, in one, the people "as a whole are maternal and feminine in temperament". In a second, she found them "ruthless, aggressive, and positively sexed;" and in a third, men were like women and women were "dominant, impersonal, managing partners". Without Bernard's challenging Mead's assumption that an entire population may have a personality that can be sensed and described, nevertheless the vocabulary of her analysis was open to misunderstandings: "feminine", "masculine”, and so forth. He wondered,

How could one set up a scientific study to test her generalizations? First of all, there must be some clear-cut definition of terms. What do we mean by 'temperament'? Do we mean acquired

24 Freeman (1983) 282, 302, and Crook (2007) 125-54 on the relations of Boas, Benedict, Mead, and Mead's second husband Reo and romantic partner Gregory Bateson, very much a Bloomsbury group; Roscoe (2003) 583, 585, on Mead's bringing a "theoretical gestalt" to Papua New Guinea and in fact finding just what she wanted within a few days of arrival; response by Leonardo (2003) 593ff. with reference to various agenda-tilted treatments of the Arapesh in New Guinea; Tooby and Cosmides (1992) 44 on what might be called scandals even in anthropology, beyond Mead's faults; Bennet (1998) 954 on difficulties confronting attempts at restudies; but corrections to field notes sometimes successful, as e.g., in Knauft (1987) 458, reviewing several "peaceful” characterizations.

25 Quoted, Kuper (1996) 188. It is striking, how introspectively unhappy the discipline appears in its publications, witness, e.g., Spain (1982), Kuper (1996) 52f. and passim, Bennett (1999) passim, or Fish (2000) 553, 559, and passim.

26 See in Chap. 3 nn. 35f., 51, and 54, regarding the nature of rationality in preliterate societies, argued in books from the 1980s onward, by M. D. Sahlins (e.g., 1995) and Obeyesekere (1997) with a continuation in, e.g., Bolyanatz (2004), who presents it as "the anthropological debate of all time" (109). 
traits like 'bravery, hatred of any weakness, of flinching before pain or danger'...? Obviously, if we define temperament in such terms, there can be no question of cultural conditioning. Not even the most confirmed believer in innate characteristics would, I believe, argue that these traits were inherited... these are not matters of temperament so much as of mores.”

And Bernard goes on to imagine a biaxial measurement in which the line "cholericphlegmatic" crosses that of "melancholic-sanguine", and Mead's three preliterate peoples can each be situated in the picture. Yet "no one," he argues, "ever claimed a sex bias in these temperamental types in our own culture. Women as well as men have about as good a chance to be one as another... At any rate, once temperament is defined, the next step is to measure it”, by such things as basal metabolism tests or tests of glandular function. These could be applied then to Mead's three populations. Where, however, no such measures were in fact made available, they are badly missed, and when, rarely, they were attempted by Mead herself, the numbers translated into nonsense. "In brief, what we really hunger for is not only the fascinating cases that Miss Mead presents so well but also frequency distributions, measures of deviation, and dispersion, etc." With still further discussion, her findings about sex roles and temperament dissolve into nothing. ${ }^{27}$ Bernard had (as Freeman was to do, many years later) in effect applied replication as a test.

In aiming at rigorous argument it was natural to extend it with that other standard instrument of the scientific inquiry, quantification, even of quite unlikely subjects. An example is the tee mentioned above, or continuity of marriage customs among the people of Kédang in Indonesia - though of course too much quantification could be ridiculous. ${ }^{28}$ It served very well in controversies. Derek Freeman in 1983 - after his own years of residence in Samoa, talking with Samoans old enough to remember the times and customs that Mead had described in 1928 - took issue with Mead's lines of reasoning, as Bernard had done; but, in addition, he questioned the reliability of her observations, which Bernard had accepted as the starting point of his criticism. Just how well had Mead been able to do her job among the Samoans? Her field notes could be taken as the database; but they revealed a very brief and incomplete immersion in Samoan life; also an ignorance or disregard of many (and discrepant) descriptions of that life by previous observers over a full century preceding her residence. Measured against statistics from twenty years later, Mead's statements about suicide, adoption, and so on didn't hold up. ${ }^{29}$

27 Bernard (1945) 176f., on Mead's New Guinean Arapesh, Mundugumor, and Tchambuli, and 179f. on their study (quoted); further criticism of her Procrustean treatment of evidence to make it fit generalizations, or careless mis-reporting, in Brown (1965) 164-71; and Sullivan (2004) 184.

28 The tee at note 7, above; Feil (1988) 104; on Kédang near Timor, Barnes (1980) 87. In Gouldner and Peterson (1962) 375 and passim or Gluckman (1965) 35f., examples of "mensuration gone mad"; Novick (1988) 383ff., on the vogue of quantification setting in among historians post-WWII.

29 Freeman (1983) 123-71 passim, 203ff., 185 and 202 (virginity-tests), 221 (suicides), 259-67 (teenage delinquency and crime). Since nineteenth-century observations and those that Freeman could quan- 
A second prominent instance of quantification in controversial matters concerned "the Fierce People", the Yanomamö (Yanomami) of the Amazon basin around the Brazilian-Venezuelan border. It was Napoleon Chagnon who most fully reported on them in 1968 and subsequently. He lived among them for decades, particularly among those found in one certain large area (Kaobawä). Here, "warfare, violence and abduction of women have been extremely important factors in their history as far back as I can trace it with informants who are very old - perhaps in their 70s or 80s in 1964 when I began my work. They have long since died”. In about a dozen villages with a population of nearly 1,400 in 1988, he made a careful count of those who killed more than once, or themselves had suffered a violent death, or had lost kin in such a way. ${ }^{30}$ It was an unusual sort of census, unusually precise, in answer to critics who had challenged the characterizing of this people as "the fierce".

Questionnaires could yield quantifiable assessments of tribal values, asking about human nature (is it good? or bad? and how do we relate to nature, or to the past or the present?). ${ }^{31}$ For practical purposes, polling was used by David Smock in a district of Nigeria, where the government in 1966 proposed to establish and fund communal palm plantations. Where would such projects be most likely to receive good support and attention from the residents, given that no harvest from the investment could be expected for five or six years? Which villages had a collective character best suited to succeed, qualifying, for instance, as "more self-reliant", "more likely to believe that by working harder they can improve their position", or "more fully imbued with the puritan ethic and the entrepreneurial spirit"? "The puritan ethic came out in a questionnaire asking whether respondents thought it advisable to forego immediate pleasure in order to achieve more lasting satisfaction in the future". The point of the exercise was to identify in percentiles the traits that would be "predictive". ${ }^{32}$

Rorschach testing, too, was used to detect personality traits in a given culture from the 1940s on. In illustration: gross differences could be measured between two groups of European descent in Western America, and two groups that were Indian, but also differences between the two members of the latter pair. It was possible also to distinguish in numerical terms some of the dominant aspects of character among

tify fitted well together, there was no reason to think that Mead's Samoa had really been different. 30 Chagnon (1997) in the fifth edition, with changes from the first of 1968, at page 204. The controversy over "fierceness" became embroiled in serious charges principally against a certain Neel but also Chagnon, brought by a journalist Tierney (2000), and supported in a sourcebook and syllabus with stimulating questions for students by Borofsky (2005), the whole collection being tilted against Chagnon. However, a supporter R. Hames (121ff.) is quoted on the Chagnon side, and Gregor and Gross (2004) add still more to correct the balance.

31 Henrich (2005) 799f. on testing for reciprocity-values in very remote villages of several continents; similarly in Newson et al. (2007) 462f. on market-values; and further, questionnaires put to a range of wealth-levels, Haidt (1993) 614, 617f.

32 Smock (1971) 60-72 passim. 
Eastern American and Canadian Indians and how deeply rooted these aspects were in the psyche of persons tested. A. Irving Hallowell made the case, with due caution:

If it be assumed that personality structure is, in large part, a product of training, experience, and psychological integration that is directly related to the cultural variables that constitute the individual's group-membership situation; and if it be assumed that reliable information on personality structure can be inferred from the manner in which the subject responds to the stimuli presented by the Rorschach figures, then it must be granted that the data obtained in this way are psychologically significant...

and Hallowell continues, that without such anchorage in shared perceptions, "the individual... could not function effectively". As others put it, in the absence of valuecoherence (which is the culture), the "social system would cease to work". ${ }^{33}$ Thus by scientific testing the most essential collective traits could be shown not only to exist but could show how they came to exist, through being internalized.

The existence of collective character remained a given, and its resemblance to national character was noticed, too. Anthropologists not unreasonably arrive at and share their overall impression of their subjects, drawn in broad strokes though needing improvement over the course of longer residence and deeper inquiry. It is assumed that in every people there really is a collective character to be discovered. The notion pervades anthropological publications and analytical discussions. ${ }^{34}$ "It

33 Early Rorschach use by A. Kardiner and others, cf. Manson (1988) 70f.; Hallowell (1955) chap. 3, esp. 39 (quoted), 42f., 143, 149; Kaplan (1954) 329; Spiro (1999) 12 adding nuance to Kaplan's studies, where also by a different method (a questionnaire) Kluckhohn and Strodtbeck (1961) 80-90, 138, and passim, had found similar significant differences. On the absolute necessity of value-coherence, see statements in Fortes and Evans-Pritchard (1940) 20 (quoted, “cease to work") or Strauss (1992) 8; or Kaplan (1954) 320, Kuper (1996) 52, or Rousseau (2006) 76, saying shared values insure conformity and communal harmony.

34 Above, nn. 4, 29; the Zuni "a ceremonious people", Benedict (1934) 59, 78; "war alone is the dominant concern" of the Prairie Indians, Boas (1936) 266; "the will to superiority" is central in Kwakiutl character as Benedict saw it, Codere (1956) 334; "proud, excitable, dramatizing," the New Guinea Iatmul, Bateson (1936) xxii; the "callousness" of Balinese, in Mead, quoted, Wikan (1989) 297, who are "progressive and unconservative," Manners (1956) 165, and "measured, controlled, graceful", Hollan (1988) 52 or Just (1991) 290; among the Nuer, "simplicity, single-mindedness, and conservatism," etc., Evans-Pritchard (1940) 30, 130, 151; the Ilongot loud, eager talkers, gesturing, exclaiming, expressive, Rosaldo (1980) 14; the Camayuras "a happy people full of good humor", Weyer (1955) 121; the "coarse and dull" Mailu of the Trobriand Islands, Malinowski (1979) 5; the Kede "adventurous, courageous," etc., Nadel (1940) 195; the Borneo Ibans "the wickedest headhunters in the whole world", Vayda (1976) 48; the Northeastern American Indians "stoical", Hallowell (1955) 133, 144; the "passivity and docility" of the Swazi, Nader (1990) 296; "self-control and restraint" of the Javanese, Just (1991) 290 or Geertz (1960) 367; "harmony, reciprocity, and moral behaviour” of the Venezuelan Piaroa, in Rousseau (2006) 102; or on Manus island, "a puritanical, materialistic, driving people”, Crook (2007) 132. In a survey of perceptions of "cultures" across the last century and a quarter, Triandis (2007) 64f. and passim assumes the separate, distinguishable existence of cultures in scores of thousands 
is a common impression of those who visit foreign countries," wrote Gregory Bateson apropos Ruth Benedict's work, "that the natives are either faster or slower, brighter or duller in their reactions than the members of the observer's community. This impression is no doubt due to some form of cultural standardization of the personalities concerned." 35 Or again, the conclusion is drawn from a variety of cultural anthropologists, that "most cultures have a few basic principles that classify and evaluate broad ranges of behavior and/or emotion. Such key orientations establish ideals and values, and can be crucial to an understanding of motivation." ${ }^{36}$ And, looking a little more deeply, we have Victor Barnouw in his description of the Navaho and other Indians: "modal personality [may be] defined as the sum total of learned cultural behavior" and "the theory that modal personality patterns play a significant role in historical events seems important and one wishes that historians would take note of it”. Marshall Sahlins agrees: “The claim is not that culture determines history, only that it organizes it." 37

To take the next step and apply a further lesson from anthropology, a key term here needs clarification. Should "cultural" be treated in rationalist fashion, and as the active, shaping force of its member-population? Instead, is culture itself shaped by a modal personality? Or (in nominalist fashion) perhaps culture is the modal personality aggregated? Boas, Benedict, Mead and many others had made such questions familiar. In criticism, on the level of logic, the circularity of their reasoning could be pointed out; and it could be added, as a matter of observed fact, that "any culture is a system of expectancies: what kind of behavior the individual anticipates being rewarded or punished for... For this and other reasons (e.g., the strongly affective nature of most cultural learning), the individual is seldom emotionally neutral to those sectors of his culture which touch him directly". By this latter formula the whole matter of collective personality is firmly seated in the living minds of the society's members, not in the imaginary world that lies beyond the philosopher's cave. ${ }^{38}$

world-wide.

35 Bateson (1936) 177 (quoted).

36 Knauft (1985) 61, and (2) as illustration, his finding among the Gebusi "the dominant ethos is one of self-effacement, easy humor, and friendly deference;" again (1987) 459.

37 Kaplan (1954) 334; 319, instancing a student of Clyde Kluckhohn's, V. Barnouw (1950) on the Chippewa; and Sahlins (2004) 11, quoted.

38 The "modal" personality, in Kroeber and Kluckhohn (1952) 166, Kaplan (1954) 319, 334, Kuper (1996) 149 on Malinowski's "people's model", Spiro (1999) 7f., or A. F. C. Wallace cited by Sullivan (2006) 643; 641, on Mead's perceived equating of individual personality with culture; Mead's characterizations in Bernard (1945) 176 or Freeman (1983) 90, and Benedict's in Benedict (1934) 131 of the Dobuans. On the circularity of supposing that culture shapes individual behavior, where culture in fact is shaped by individuals, see, e.g., Freeman (1983) 74 on Benedict's and Mead's "theory of culture as 'personality writ large”"; Codere (1956) 334, quoting Benedict (1934, 222) on "the ideal man" of the Kwakiutl. See also Kuper (1996) 184 on Boas' students; better, Kroeber and Kluckhohn (1952) 157 (quoted, on "expectancies"); and Bennett (1999) 952. Impatient of all "stereotyping” as he sees 
But whether it is to be found in the living mind or is rather modal, the personality prevailing in a given culture must have as its foundation whatever can be found in every culture, demonstrably universal. Quite aside from urges or drives, Darwin pointed out how contractions of certain facial muscles in Man (as also in other primates) convey identical emotions cross-culturally and, on this foundation laid in 1867 and 1872, the most recent discoveries by psychologists have built, to confirm his findings beyond dispute and to greatly extend them, too. ${ }^{39}$ A half-dozen emotions are favorites (anger/rage, fear/anxiety, disgust, sadness, joy/happiness, interest/surprise) but others must be added. Laboratory means can show them to be mostly under the control of the autonomic nervous system and distinguishable from each other, in whatever age of subject or cultural context. Of the six most often listed, anger can be shown to last longest; most obviously, to spur action; and to do so most strongly. Heart-beat, breathing, and skin temperature are affected. It seems likely, however, that facial expressions, or the raised voice or tears or "any component of emotion can assume this initiating role". ${ }^{40}$

Hard-wired behavior, so far as it shows in facial expression, might sometimes appear to deviate from the accepted universals according to the people studied, as, for example, in displays of anger. ${ }^{41}$ Appearances, however, are deceiving: the feelings really are there but it may not be the choice of a people to let them show. What will be reported by observers trusting only to their own eyes must be corrected by laboratory tests and comparative findings; and these will better reveal the universals. It is only tradition and custom that make them look different.

The extent to which universal elements control patterns of behavior and account for the shape of whole cultures, anthropologists have debated as much as psychologists. I reported some of their discussion in the preceding chapter; I return to it in the next chapter, too. ${ }^{42}$ In both disciplines, discussion has lingered on the significance of behavior deviating from perceived norms and on the degree of plasticity in human

it, Hofstede (1994) xi declares flatly, "a culture does not consist of modal personalities; culture is no king-size personality".

39 Darwin's article in Notes and Queries on China and Japan, 1867, precedes his Expression of Emotion in Man and Animals, 1872, where Tassinary and Cacioppo (1992) 28 date the beginnings; cf. MacMullen (2003) 59; and on proposed basic emotions, 53f., 59f., as also in Levenson (1992) 23f., Zajonc and McIntosh (1992) 72, or Fish (2000) 556; and on universals, above, chap. $1 \mathrm{nn} .1$ and 29-34, and below, n. 43.

40 On forceful anger, Levenson (1992) 24 or MacMullen (2003) 77; and quoted, Levenson (1992) 26.

41 Fish (2000) 556; on the role of display rules and consequent differences which can be shown up as cultural by lab tests, see, e.g., Tassinary and Cacioppo (1992) 28f., and Ekman (1992) 35 or MacMullen (2003) 71, anger displayed by Americans compared with Japanese.

42 Perhaps first in Benedict, see Freeman (1983) 74, culture is "personality writ large"; later, Kuper (1996) 184; or the two can't be kept separate, Hallowell (1955) 33, and Eggan (1954) 55 agreeing; or socializing forms personality (so, Mead and Benedict), in Voget (1964) 484, 486, Nadel (1940) 195, Sullivan (2004) 188, or Murty and Vyas (2006) 627. Further, see below, nn. 54ff. 
beings in the process of their socialization. Were they susceptible of absolutely any formation by their parents and other members of their community? Nature was proposed as at least very important in the outcome; then nurture commanded the field; more recently, champions of nature seem to be again ascendant. ${ }^{43}$

To illustrate plasticity, consider two cultures in the southern Pacific. One of the pair is found in Tahiti; the other, well to the west of Tahiti but with the same climate, in Truk. This latter is a lagoon embracing a number of tiny islands. While both members of the pair present "an image of the tropical paradise", the Truk population must venture beyond the walls of the lagoon for each day's subsistence, out in the open water, with effort and risk. The men are a fierce, macho folk. In Tahiti by contrast, males show none of the Truk competitive and possessive behavior. Relations between the sexes in the two populations reflect these differences also. ${ }^{44}$ It would be easy to point to other pairs like the Tahitians and Trukites, showing how one and the same human material can be made into two quite different ways of life in response to their surroundings. ${ }^{45}$ Response will reveal an existential or functionalist logic.

But not entirely and not always. A second pair show quite different adaptations to essentially the same environment. Among the Kede people along the banks of the Niger, those upstream do some fishing but mostly farming while those adjacent to them downstream have extended their fishing to trade and transport. These latter over time have become the carriers of everything that moves on the river, thanks to their willingness to take risks, embark on trips of many weeks, and venture among quite other populations. They "are adventurous, courageous, possessed of a spirit of enterprise." 46 The differences within the two Kede peoples developed from within the community without regard to subsistence or what might appear to be the logic of the situation, at least in any subsistence-driven fashion.

Still further along the spectrum of nurture-shaped ways of life, the Kiriwinan islanders and the surrounding Melanesians offer a good example in their kula, described as "a pursuit of immense importance to the natives, and playing on almost all

43 On deviance as observed and how it should be explained, see Wagner (1940) 202f.; Bernard (1945) 179f.; Brown (1965) 165; Manson (1988) 114; Kuper (1996) 149-52; Brubaker (2004) 49ff.; and Sullivan (2006) 603. On a tilt toward hard-wired universals, see, e.g., on Mead or Benedict, Voget (1964) 484, or Sullivan (2006) 644; the differing emphases noted by Helbling (2006) 156, 168f.; on universals being favored, see, e.g., D’Andrade (1992) 24, Cosmides and Tooby (1992) 207f., Spiro (1999) 9ff., and especially Barkow et al. (1992) passim. Zajonc and McIntosh (1992) 71f. review the good neurological evidence for distinct mental states identifiable as appetitive or aversive, cross-culturally; further, on these and universals, Levenson (1992) 23f., Ekman (1992) 34, Fish (2000) 556, or Rousseau (2006) 76, on "values that form part of our species' make-up: food, sex, sleep, security, company".

44 Nisbett (1990) 259f.

45 E.g., Newcomb (1950) 318ff. on Dakota, Cree, and other Indians, or Ross (1984) 90f. on different branches of the Peruvian Jivaro.

46 Nadel (1940) 195 (quoted) and passim. 
of their social passions and ambitions." Its origins lie some hundreds of years in the past. ${ }^{47}$ Bronislaw Malinowski is quoted in a book that first brought attention to the kula. The custom or institution recalls one common in American high society a century ago, in which people left calling cards with their friends and acquaintances, sometimes adding a few words of greeting; and it was a thing to be proud of if one's silver plate on the hall table had lots of cards left there to show the next visitor how sought-out the recipients were. Similarly the kula enlisted the whole population of scores of little maritime communities on scores of islands of which the Trobriands are the best known. Emissaries from them sailed around to each other in outrigger canoes, in the less perilous seasons, leaving off and receiving in exchange decorative shells, often inscribed. The shells were of two species, and the carriers of the one coasted about in a counterclockwise direction, taking weeks or months on the circuit, while those of the other species went clockwise. Shells were valued for their previous owners, whose lineage could be traced and would be well remembered. Carriers who returned home with specially storied shells to be worn or displayed in their home drew praise and prestige upon their communities and themselves. Leadership status in their homes depended significantly on one or another aspect of the kula.

Yet it had nothing to do with subsistence. Deeply penetrating the lives of everyone directly or indirectly involved, holding its place in that remote Pacific world over the course of countless generations, the kula exemplified in remarkable fashion just how much a way of life could be constructed without material logic. As Malinowski insisted, it "contradicted in almost every point" our modern economic literature and notions of exchange.

All its main transactions are public and ceremonial, and carried out according to definite rules.
It is not done on the spur of the moment, but happens periodically, at dates settled in advance,
and it is carried on along definite trade routes, which must lead to trysting places... the Kula is
not done under stress of any need, since its main aim is to exchange articles which are of no
practical use.

The point Malinowski wanted to emphasize here he made again through his description of how the same people took care of their basic subsistence. They depended principally on a staple, yams, that men grew in the family garden. What struck the observer most was the pride that was taken in making one's garden not simply productive, but pretty and neat and embellished. At the end of the season, too, it should produce a yield sufficient to feed all dependents, all guests, absolutely anyone who asked; and in fact a great deal was left to rot, since there were no takers. The owner could expect general applause for all this; that was his reward. In contrast,

47 Malinowski (1922) 73; on a kula article datable to between 500 and 2000 years ago, see Malnic (1998) 16. 
A notion which must be exploded, once and forever, is that of the Primitive Economic Man of some current economic text books. This fanciful, dummy creature, who has been very tenacious of existence in popular and semi-popular economic literature, and whose shadow haunts even the minds of competent anthropologists, blighting their outlook with a preconceived idea, is an imaginary, primitive man, or savage, prompted in all his actions by a rationalistic conception of self-interest, and achieving his aims directly and with the minimum of effort. Even one well established instance should show how preposterous is this assumption that man, and especially man on a low level of culture, should be actuated by pure economic motives of enlightened selfinterest. $^{48}$

What brought Malinowski to a boil was the dismissal of the primitive as hardly human, on a level beneath that wonderful invention of his own academic world, homo economicus. The Kiriwinans whom he knew and some of whom he valued as friends were in their fundamental nature no different from himself. What, after all, was meant by "rational", the term of praise? It looked only to "practical use" and "utilitarian purposes". In his own observation, social institutions, structures, or the modal personality (not that he used the term) could not be explained solely through subsistence needs, material benefits, security against hostile neighbors, or similar factors. They developed in more complicated ways out of a different logic. They were much more the invention of a community, over time, and require a wider definition of rationality - a matter reserved for the next chapter.

To this point, my discussion has been concerned with the external features of generally small, preliterate populations, as they appeared to visitors from a more complicated world - my object being to note whatever these latter noticed that might also illuminate the large populations of more formal history. The most striking observation made by visitors, it seems to me, is the governing personality they are able to identify, or think they can identify, in whatever group they may be studying. From this, observation will turn to the constituents of that personality, of which some will be universal and of our species, and will dictate behavior directly: as, for example, the reproductive urge. Others, for example governing speech or nurturance, find expression in traits particular to a culture. ${ }^{49}$

They are the product of that most delicately interactive relation whereby each individual helps to define the collective way of life while being at the same time

48 Malinowski (1922) 59; and in other writings always insistent that "while the 'savage' may be no more rational than ourselves, he is at least as reasonable" (summed up thus by Kuper 1996, 23). Compare the similar tee, "'irrational' in the logic of modern economics thinking”, in Feil (1988) 108, or "the essentially nonutilitarian, or surplus, nature of feasting" in various tribal settings, Hayden (1995) 22, often noted, cf. e.g., Malinowski (1922) 172; care taken by Harris (1984) 113f., not to call Yanomamo belligerence irrational simply because it was not materially profitable; similarly, Newcomb (1950) 319, on warfare as seen and waged by several of the Plains peoples, not really "an economic war"; and more generally on "nonmaterial dimensions of behavior," Blanton (1995) 106.

49 A debate of little concern to me, but see Newson et al. (2007) 454, 457, indicating its outlines and the proportion of causality, split between the hard-wired and the culturally acquired. 
shaped by it - a never-ending process which anthropologists go on to explain in more detail, focusing above all on the coherence of the result. On this, as they say, existence itself depends (above, at n. 33); according to its rules everyone must do things the same way. It is expected. Conformity is taken to be, at least in part, response to the existential demands of the immediate environment; yet function by no means explains everything, neither tee nor kula nor rituals of many sorts which have somehow become, and so simply are, the custom. They determine proper conduct in whatever role or position one acts: as parent, child, warrior, medicine man, forager, wood-carver, but above all, as a good group member.

In the forming of a collective character, no moment could be more unguarded or revealing than childhood. Here, observers have been on the watch for the first signs of personality typifying a people and destined to develop into adults who will reify that people's most distinctive values. ${ }^{50}$ At one extreme have been the investigators who thought they could see a group personality emerging from the very earliest months of upbringing. In consequence, much analysis of weaning was needed, and of sphincter control and of what a non-believer mockingly called "diaperology". ${ }^{51}$ In time, interest in anal and oral experience and other Freudian elements in the forming of the members of a culture, and so of the culture itself, seems to have faded, but without diminishing interest in the guidance provided to children by parents and close kin. Emotional ties and rewards and how they worked and their huge importance in the forming of little children have been noted; ${ }^{52}$ observation and imitation of others as well, quite unguided at every young age; ${ }^{53}$ the forming of teenagers also, as for example among the New Guinea Iatmul, where a public celebration will be staged

50 Begin with childhood: so, Margaret Mead in Sullivan (2004) 189, Kaplan (1954) 334, Lutz (1988) 107f., Strauss (1992) 8, or Murty and Vyas (2006); ferocity taught to Nuer children "from their earliest years," Evans-Pritchard (1940) 151; to Iatmul children, Bateson (1936) 4; to Maori, Vayda (1976) 81; to Yanomamö children, Chagnon (1997) 127; to children of New Guinean "warfare societies", Boehm (1999) 95; generosity and sharing, to Bemba children, Gluckman (1965) 52, to Solomon Islanders, Hogbin (1970) 35, and to Murngin children, Peterson (1993) 863, 866; club-forming to Nyakyusa boys, Wilson (1963) 67; suspicion of strangers, to Kayan children, Rousseau (2006) 77; non-competitive behavior to Samoans, Freeman (1983) 88; no fighting, to Zuni children, Whiting et al. (1956) 95, or Briggs (1970) 137 and passim on the Utku; civil, peaceable manners to the Balinese and Toraja, Hollan (1988) 52-55, and to Dou Donggo, Just (1991) 298ff.; and the group personality stubbornly perpetuated in children, Hallowell (1955) 39. But notice the report of Goody (1991) 120, "Most of the patterns of learning prosocial behaviour... have not been the result of formal teaching. It is seldom possible to know what the adults had in mind when they shaped... behaviour because the ethnography seldom addresses the question".

$51 \mathrm{M}$. Mead even pronounced personality types to be characteristic of a group by inheritance, genetically, see Sullivan (2004) 187f. Especially Abram Kardiner championed Freudian theory in cultureformation, see Manson (1988) 52f., 96f., Kaplan (1954) 319f.; also Quinlan and Quinlan (2007) 168; and “diaperology", Manson (1988) 106.

52 For example, in Briggs (1970) passim or Goody (1991) 106-19 and (1992) 13f.

53 Haidt (2001) 828. 
by a proud mother for the daughter who returns from her first successful fishing attempts, or among the Malawi Nyakyusa:

...often a man would say to his son 'Don't you hoe for me, I'll do the hoeing myself, you go and swagger about.' Sometimes a man would sell a cow and buy a huge-bladed spear and give it to his son. Then, if he heard that his son was a fierce man in war, and always quarreling with and spearing his fellows, he would say with pride: 'He is my son!' And if he heard people saying: 'The son of so and so is a fierce man', he would rejoice. ${ }^{54}$

In these latter pictures the whole community is seen functioning as a school, teaching lessons in the behavior most approved by adults, to adults. Their value system can be sensed in their myths and stories. Public symbols, rites and speeches are equally useful and open even to an outsider. ${ }^{55}$

What is taught at the knee, respect for one's elders, is a value spelt out in larger terms by the prominence, or often the special privilege of speaking to one and all, that belongs to older members of the community. ${ }^{56}$ The privileges of age shade off into ancestor worship. This in turn shades off into an awe that is the proper tribute paid to all inherited tradition. ${ }^{57}$ Awe invests the spirits, the gods, and those living mortals, elders, priests, medicine men, or chiefs that know their lore. Such persons act to affirm and protect things as they are. ${ }^{58}$

Often instruction is in a positive form, that is, through noisy advertisement of something or someone perceived as good: the "furious competition" of potlatch, the parade of successes in kula or tee exchange, or the display of trophies from a raid on a neighbor. ${ }^{59}$ The community serves as the audience to learn an individual's "claim to a place in society". Status is didactic: there are the more honored ones, speaking while

54 Bateson (1936) 17; Wilson (1963) 79f.

55 For myths and stories with a moral, see Nader (1990) 55 or Mathews (1992) 127ff., 159; the community as teacher, especially in Bateson (1936) 4, 141, and passim, also Hogbin (1970) 37f.; Boehm (1999) 73f.; Munn (1986) 211, 234-66 on “didactic speech”, or Just (1991) 299f., 303.

56 In Melanesia, Malinowski (1922) 37; among the Ibo, Meek (1937) 112f. or Jones (1971) 67f., 71; among the Zuni, disrespect for elders is punished, Whiting et al. (1956) 102; an Arab “theme”, Barclay (1971) 292; age privileged among Zambesian Lozi in judges' panels, see Gluckman (1965) 39; also among Arusha in Tanganyika, Gulliver (1963) 38, and the Brazilian Camayuras, Weyer (55) 108, and the Gawans, Munn (1986) 42; and elders are better fed at feasts, Wilson (1963) 71.

57 On "the weight of ancestral custom" among the Bantu, see Wagner (1940) 202; "ancestral authority” among the Ibo, Jones (1971) 65; fear of angering ancestors, e.g., among Solomon Islanders and Admiralty Islanders, Hogbin (1970) 45 and Crook (2007) 132.

58 Arab veneration for holiness, Barclay (1971) 303; among the Ibo, the foundation of law, or at least sanctions, rests in religion, Meek (1937) 20; power based on monopoly of religious lore among the Hopi, in Rousseau (2006) 182, cf. Plog (1995) 193, more generally on the pueblo; similarly among the Tsimshian and Kwakiutl, Ames (1995) 175, and the Hopi, Plog (1995) 193.

59 The potlatch-quotation, Gluckman (1965) 77; public defense of the tee system, Feil (1988) 107; “claim to a place," quoted, Voget (1964) 487 and $492 \mathrm{f}$. 
everyone else is silent. As a child observes and learns from observing and mimesis, one must bow to them, uncover one's head, kiss their hands. "When the chief sits down, no one would dare to stand." 60 Teaching may also be through negatives. What is seen as wrong invites the shaming of the deviant. Most of this goes on more or less informally but it is nonetheless effective. ${ }^{61}$

We hardly need to be told why. Talcott Parsons and Edward Shils pointed out how "the need to be approved and esteemed is a fundamental motivational basis for the acceptance of socially necessary disciplines... the core of the reward systems of societies is to be found in the relevance of this element of the motivation of individuals." It is a truth as old as Aristotle, and a very foundation-stone in the social theory of France's well known Pierre Bourdieu, who quotes the Greek philosopher: Man is, of all species, the most prone to copy his cospecifics, mimetikotaton. He learns by doing what others do. And just as a whale is a marine animal, so Man is also a community animal, politikos, and within that community, depends on its support. Bourdieu offered many vivid illustrations of this and other ideas out of his anthropological work in North Africa, where "doing one's duty as a man means conforming to the social order" and where the culture's general "dispositions" govern not only what a person intends but how he anticipates others will respond; for everyone responds to the same expectancies. ${ }^{62}$ More recently Claudia Strauss drew such observations together: "Given that human action is certainly underdetermined, if not undetermined, by innate drives, we do indeed have to examine the cultural sources of motivation, including the social behavior people observe, the instructions they are given, and the constructed realities they bump up against."63

Socialization is of interest to other disciplines than anthropology, of course (see chap. 3, below); but as to the objection that one of them, psychology, might be better

60 Kiss the hand, etc., the Aymara in Bolivia defer to the Mestizos, Barnouw (1985) 40; quoted, Malinowski (1922) 52.

61 Shaming and mockery noticed among the American Indians, cf. Hallowell (1955) 133; among Tonga of Rhodesia, Gluckman (1965) 98, and Samoans, in Freeman (1983) 89; Kabylians, also, in Bourdieu (1977) 162; the cost to the shamed, above at n. 9.

62 Quoted on "the need to be approved", in Parsons and Shils (1962) 150. In Aristotle, Politics 1.2.9, 1253a, politikos is often translated "social"; further, his Poetics 1448b, in Bourdieu (1977) 96, with the statement in Malle (2008) 275, that "humans are the only species in which members instruct each other by demonstrating a novel behavior and inviting the other to perform it in turn. Complementarily, humans are exceptional observational learners”. Further, Bourdieu (1977) 161, drawing on Kabyle observations to make concrete the "various ways of reasserting solidarity" with one's society, through conformity, where anything else is suspect; 72 and 214 on "the system of dispositions" which he calls habitus and its function in determining individual strategies of behavior; Hunt (1989) 13f., defining Bourdieu's habitus; and Goodman (2003) 783-86 on Bourdieu's understanding of proverbial wisdom as fossilized values; and on the individual's action emerging from a cultural structure, cf. Ortner (1989) 13.

63 Strauss (1992) 8; and on motivation, further, above, nn. 31f. 
heard from, there is a good answer. Psychologists indeed command laboratory science in all its enviable depth and exactitude; but they generally focus on the young men and women they find handy in their own classrooms, and such a test group can constitute only "an extremely narrow cultural base on which most broad behavioral generalizations are constructed". ${ }^{64}$ Better, then, an approach through the comparative study among very different, simpler populations, looking for consistencies without necessarily looking for natural laws.

Consistencies are barely detectible among hunter-gatherers, the least cohesive of peoples; but elsewhere they are essential (above at n. 38). Agreement, prescribing the loyalty owed to one's kinfolk, begins with one's immediate family and then reaches out through marriages. On this, the most general Leitmotif, our species has devised endless variations. They are of particular interest to anthropologists; for, whatever culture is studied, its members so often manifest a quite extraordinary knowledge of who their agnate and cognate relatives are or were, in distant generations, and, therefore, who in the community is owed this or that particular service - who has a right to it. As an extreme instance, witness the Gahuku-Gama of New Guinea, among whom there is no general ethical system at all, no single set of rules about right and wrong, but only according to familial relation; so it is bad to kill your mother's kin in a fight with the neighboring tribe, but good to kill anyone else. ${ }^{65}$

Of networks thus fashioned out of a definition of duty, a clan can make a workforce or a war-force. It may then accumulate wealth and prestige. Its success validates the ties of obligation that may be extended beyond the clan through a system of exchange or the like, to tee brothers, eating clubs, or age groups. ${ }^{66}$ In this manner a "structure", a "simpler culture", can emerge. Within it, everyone knows where he or she fits and what is due to whom.

The term "structure" opens up a very large technical literature and all its discussions over a full century. How various its forms could be appears among the North Coast Indians that Boas studied, and others after him. The unit of control was determined not only by descent but by residence as well, each with its chief; and

chiefs had considerable power to organize production, public ceremonial, and ritual. They had the power - and obligation - to accumulate and display the wealth employed for potlatching. This power is balanced by their lack of power over free individuals and the limits imposed on their power by councils, and by the ability of household members to vote with their feet by leaving the household, or even to establish a new House. ${ }^{67}$

64 The fact bears repeating from chap. 1 at n. 35; Fish (2000) 553 is quoted), adding "e.g. 80\% of the articles in social psychology journals are experimental studies of undergraduate psychology students".

65 Shweder and Bourne (1984) 167f. (observations of the 1950s).

66 Feil (1988) 104; Nyakyusa, Wilson (1963) 68; and on Arusha, Gulliver (1963) 28.

67 Ames (1995) 178. 
Power thus has an objective existence, at least as it is seen here. Like muscle, you may simply have it, much or little. But the underlying assumption here is realist, not nominalist. While it serves most descriptive purposes well enough, for analytical purposes the fact must be confronted that nobody has power. In all respects, "sociocultural systems can be said to exist concretely only in individuals". ${ }^{68}$ Power is a relationship without existence outside the minds of any two or more of its members, the one directing, by what the other acknowledges as a right, while that other complies; and compliance is seen as a duty. Leaders, if they are accorded obedience, do indeed control muscle that may be sufficient to compel others who belong neither to the clan at all nor to the club. Against compulsion, appeal can only be directed to some other part of the network, as for instance to a council, or to an entirely different structure of obligations, as for instance that larger community that embraces the whole House - thus, for example, in the potlatch people just referred to. Members of this larger community will approve or disapprove of their chiefs' decision. Their decision will or will not have power - or muscle. We would say it amounts to law, which in its own turn has power to the extent its commands are approved - that is, are seen as right. The only recourse from the law, as the passage quoted indicates, is to quit the society entirely; and such an act for a zoon politikon is very difficult.

We thus arrive at the Social Contract - hardly a novel finding, older indeed than Aristotle (Plato, Crito 51f.). But anthropology has something new to add on the nature of obligations that constitute the contract and control behavior. Adam Kuper calls these "sentiments of social solidarity [which] must be maintained in order to make people play their appointed parts." ${ }^{69}$ They explain leader and follower; they explain council members and appellants who fail in their suit but accept that failure. In all these can be sensed "an identification with the moral order, a respect for legitimate authority, and a feeling of disinterested obligation to live up to expectations". It can be illustrated, for example, by "motivational patterns" among the Zuni. ${ }^{70}$ They allow an insight into those feelings and sentiments and the role of the irrational in motivation in which not only anthropologists but historians as well are interested, and which will need mention often in the pages that follow.

The words italicized by myself, above, bear on a discussion among anthropologists about their most familiar term of art: "culture”. What exactly does it mean?

68 Kaplan (1954) 320, quoted ("concretely", my italics), gathering the views of a number of anthropologists; cf. the psychologist Hinde (1996) 368, "'Culture' is thus best viewed as existing in the minds (separately and collectively) of the individuals in a group".

69 Kuper (1996) 53, a formulation "plausible enough" but needing to be carried further; on solidarity, above, n. 62.

70 Parsons' thought which Kaplan (1954) 323 applies (quoted) to the Zuni, as an example; compare Evans-Pritchard (1940) 171, on clan support for fractious behavior among the Nuer because "it is recognized that a man ought to obtain redress for certain wrongs... if he is right." On "expectancies", see above, n. 38 . 
From some hundreds of proposed definitions, a consensus emerged a half-century ago: "the essential core of culture consists of traditional (i.e., historically derived and selected) ideas and especially their attached values". ${ }^{71}$ Values, proposed as culture itself and crucial to a society's function and survival, in turn would be those sentiments and feelings that Kuper speaks of (above), and which Robert Aunger further explains as "cultural knowledge [which] is not just transmitted information but the internalized derivatives of others' social inputs. [It] depends on the entire personalities of each individual: cognitive, evaluative, and affective. Through this process, some cultural information acquires emotional and directive force, and thus determines an individual's behavior". ${ }^{72}$ True, the debate continues, whether knowledge of this sort is really internalized; but it certainly forms an integral part of the individual's make-up; and the individual is himself also a part of that texture of reflexes, thoughts, and feelings that surrounds every member of the culture. ${ }^{73}$

As to "emotional force", it is especially marked where the sense of entitlement is violated. For this, the Ifaluk even have a particular term, song, meaning not plain anger but "justifiable anger", where a right has been denied. ${ }^{74}$ Song and other emotional states that accompany moral claims or reactions to others' behavior of any sort can be generally read in quite visible signs. They are known thanks to the universality of facial expression. The yield of anthropological observation may thus fairly be called scientific in the sense of being verifiable (as, for example, from photographic records).

Now, to sum up: beginning, some pages past, with the kula and Bronislaw Malinowski, three common anthropological observations were recalled in a series to describe or, better, to explain "simpler societies". First, in such societies a collective personality can always be perceived and is most often the starting point for a full account of their lives; and on this, Boas' Leitmotif, my chapter focused at the outset. Further, this personality is formed across time, in each rising generation, through nurture, group approval, and various rites and symbols. Lastly, coherence or consistency in that collective personality is a consequence of a general agreement about right and wrong, which directs behavior and is motivational in its affective wrap-

71 Kroeber and Kluckhohn (1952) passim and 181, quoted; the number duly noted in White (1968) 15; and of course endless revisiting of the definition-problem, e.g., in Kitayama et al. (2007) 138f.

72 On the crucial place of values recognized among anthropologists, see above, at nn. 31, 33, 36, 49, 53, and 67; values as the constituents of a morality, e.g. in Boehm (1999) 245; further, Aunger (2000) 448, views illustrated passim from observations in the Ituri Forest.

73 Though Kaplan (1954) 323f., 328 has doubts, he acknowledges that internalization of values is usually assumed, cf. Aunger (2000) in n. 72; and "deeply ingrained" is similar, in Vayda (1976) 81 on the Maori; above at n. 49; and after all, monkeys betray feelings of guilt, which can only be internalized, cf. MacMullen (2003) 72.

74 Lutz (1988) 165, quoted; MacMullen (2003) 67; illustrative of the range of sanctions in Wagner (1940) 203; and on anger's force, note 40 above. 
pings. ${ }^{75}$ So individuals choose their ends or goals, making their decision on how best to achieve these - while, for everyday purposes without social implications, cognitive operations come into play. It is right and wrong - that is, collective values - that are the most basic causal factor in the course of life of collectivities, to the extent that Man, not the environment, is in control.

In these three elements of our humanity thus summarized no doubt there is nothing novel; nothing new is intended. They fit with much that is commonly agreed in psychology, sociology, and economics, as I hope to show in later chapters. But in anthropology it is possible to look at them more closely and in societies different from ourselves. Let these be just such as historians must deal with, in all their strangeness: Salihid Arabs or Bogomil congregations. Here it is that anthropological insights afford good guidelines. Those most useful are not to be found on high among theories and abstractions, but rather on the plane of the concrete and objective, "writ small”, and especially in the area of values.

75 Many references to thumb-nail sketches or summings-up of a people, in $\mathrm{n}$. 34, above; socialization at nn. 43, 46-56, above; social coherence the great object, nn. 21 and 54, above; agreement internalized, n. 73, above; and motivational wrapping, nn. 33ff., 63f., above. 